\title{
Optimal design of high efficiency double helical gear based on dynamics model
}

\author{
Fengxia Lu ${ }^{1} \cdot$ Xuechen $\mathrm{Cao}^{1} \cdot$ Weiping $\mathrm{Liu}^{2}$
}

Received: 10 March 2021 / Accepted: 9 June 2021

Published online: 03 July 2021

(c) The Author(s) 2021

OPEN

\begin{abstract}
A 16-degree-of-freedom dynamic model for the load contact analysis of a double helical gear considering sliding friction is established. The dynamic equation is solved by the Runge-Kutta method to obtain the vibration displacement. The method combines the friction coefficient model based on the elastohydrodynamic lubrication theory with the dynamic model, which provides a theoretical basis for the calculation of the power loss of the transmission system. Moreover, the sensitivity analysis of the parameters that affect the transmission efficiency is carried out, and an optimization method of meshing efficiency is proposed without reducing the bending strength of the gears. This method can directly guide the design of the double helical gear transmission system.
\end{abstract}

Keywords Double helical gear · Dynamics model · Efficiency · Sensitivity analysis · Optimization

\section{Introduction}

Power loss in a gear drive system includes windage loss, oil loss, bearing power loss, gear meshing power loss, and so forth, of which the gear meshing power loss is a major constituent [1]. Many domestic and foreign scholars have proposed several theoretical models to predict the gear meshing power loss. To improve calculation efficiency, the normal load model of the tooth surface and friction coefficient model is included in the meshing power loss model.

At present, the friction coefficient model of the tooth surface mainly includes: the Coulomb friction coefficient model, the Buckingham [2] friction coefficient semi-empirical formula, the Benedict and Kelly [3] friction coefficient model, and the Xu [4] EHL friction coefficient model.

Several techniques have been implemented to deal with the normal load of the tooth surface. Liang [5], Marimuthu and Muthuveerappan [6] carried out load-bearing contact analysis of internal and external meshing gear pairs based on the finite element principle. The method assumes that the load is evenly distributed on both surfaces of the double-tooth meshing and static load is used as a normal load for the tooth surface. Kolivand et al. [7] proposed a gear meshing power loss model by combining the load-bearing contact model and the hybrid elastohydrodynamic lubrication (EHL) model. Lin et al. [8] established the theoretical calculation method of the transmission efficiency of the gear compound motion according to the gear meshing principle and obtained the calculation formula of the transmission efficiency. Liu et al. [9] and Chen and Lu [10] investigated the gear meshing efficiency under the condition of elastohydrodynamic lubrication (EHL). The authors also assumed that the load is evenly distributed over the contact line and a simplified load distribution coefficient of ISO 425E was used in the study. Simon [11] the hypoid gear on the full film lubrication mixed lubrication and the boundary lubrication analysis, puts forward a method to enhance the efficiency of the

Fengxia Lu, meefxlu@nuaa.edu.cn | 'Laboratory of Science and Technology on Helicopter Transmission, Nanjing University of Aeronautics and Astronautics, Nanjing 210016, China. ${ }^{2}$ Shanghai Radio Equipment Research Institute, Shanghai 200090, China. 
gear transmission using a multigrid method to calculate the gears meshing period, the minimum oil film thickness and friction coefficient of numerical solution of Wang et al. [12] the application of mixed elastohydrodynamic lubrication of numerical analysis method, established the model of the modified cycloidal gear meshing efficiency. Xu [4] proposed a method of calculating the power loss of a gear pair, which considered the contact point of the tooth surface in calculating the normal load of the gear. Liu et al. [13] established the transient elastohydrodynamic lubrication model of the involute spur gear and the calculation model of mechanical power loss of involute spur gear based on the elastohydrodynamic lubrication theory of finite long line contact. Chen et al. [14] deduced and established a time-varying model for calculating instantaneous sliding power loss in the engagement process of bevel gears. Marques et al. [15] proposed a tooth surface load distribution model for efficiency analysis, which takes into account the effect of friction force on load distribution based on the principle of minimum potential energy, and applied the finite element method to obtain the displacement field of the gear tooth deformation. Wang et al. [16] proposed a method to calculate the sliding friction power loss of a double helical gear. The normal load and the relative sliding velocity of the instantaneous contact point on the tooth surfaces were obtained using TCA (tooth contact analysis), and then multiplied by the integral of the friction coefficient along the contact line to obtain friction power loss. Chen et al. [17] took time-varying meshing stiffness and gear meshing contact into consideration, and systematically studied the influence of axial inclination Angle and meshing phase of gear on contact characteristics and dynamic characteristics. Mohammadpour et al. [18] established the friction dynamics model of planetary gear train based on elastohydrodynamic lubrication. The model included a six-degree-of-freedom torsional multi-body dynamics system and a tribological contact model, and calculated the oil film thickness, friction loss and transmission efficiency when the gear meshing teeth were contacted.

In recent studies, the load distribution of the tooth surface and interdental, as well as the dynamic characteristics of the gear are considered to achieve good agreement between the model prediction and the actual situation, and accurate gear meshing efficiency. In reference [19-21], the herring established in the analysis of gear dynamic characteristics and load-bearing contact took into account such factors as tooth side clearance and time-varying meshing stiffness; however, the dynamic equations did not consider the influence of the tooth friction force on the vibration perpendicular to the mesh line. The study in reference [22-24] reported that the friction of the tooth surface will lead to a significant increase in the vibration of the gear perpendicular to the direction of the mesh line and the amplitude of the translational vibration along the direction of the mesh line.

Many scholars at home and abroad have studied gear meshing efficiency. Ouyang et al. [25] proposed a lubrication dynamic model for high-speed spur gears based on the friction dynamics theory. Combined with the finite element model, the power loss and transmission error could be accurately meshing. Wang and Chen [26] calculated the total meshing power loss and average meshing power loss by the double integral method based on the elastohydrodynamic lubrication model. Li [27] proposed a formula to describe the spur gear mesh mechanical power loss under thermal tribodynamic condition. Kwon et al. [28] studied the influence of key design parameters on the mechanical power losses of planetary gear sets. Thirumurugan and Muthuveerappan [29] studied the mesh power losses in high contact ratio gear drives based on elastohydrodynamic lubrication and the load sharing ratio. while the study of star gear transmission system efficiency is relatively rare.

In this paper, a dynamic model of 16-DOF double helical gear is developed based on TCA taking the tooth surface friction into consideration. Since the Runge-Kutta method is a high-precision algorithm widely used in engineering, including the famous Euler method for the numerical solution of differential equations, which is used to accurately solve the dynamic equations to determine the dynamic meshing forces, while the pressure distribution at the tooth contact point was determined using the TCA model. A suitable calculation method was selected for the friction coefficient based on EHL. A calculation model was developed to determine the dynamic power loss of a double helical gear pair and analyze the influence of gear design parameters on the efficiency. Finally, a parameter optimization design technique was implemented to optimize the efficiency, Such modeling method and efficiency optimization method could also be used to model microscopic systems $[30,31]$ to reduce the power loss of the system.

\section{Modeling and solving the dynamic meshing efficiency of double helical gear pair}

\subsection{Double helical gear pair dynamic modeling and solution}

A coordinate system is specified as shown in Fig. 1, where the $x$-axis is perpendicular to the meshing plane, the $y$-axis is vertically upward along the meshing plane, and the $z$-axis is the axial direction of the gear. Each gear has four translational degrees of freedom in the $x, y$, and $z$ directions and 


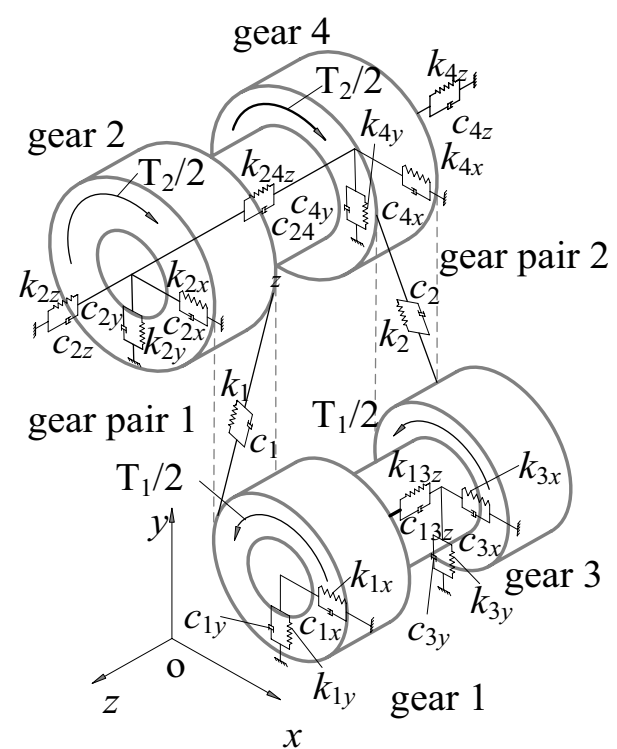

Fig. 1 Sixteen degrees of freedom coupling vibration model of herringbone gear

twists around the z-axis, with the twist direction being counterclockwise positive.

The double helical gear transmission generally adopts the small-wheel axial floating method [16]. In the above figure, $k_{m}^{l}, k_{m}^{r}, c_{m}^{l}$, and crm represent the meshing stiffness and meshing damping of the left and right gear pairs, respectively; $\mathrm{k}_{\mathrm{ix},} \mathrm{k}_{\mathrm{iy},} \mathrm{k}_{\mathrm{iz},} \mathrm{c}_{\mathrm{ix},}, \mathrm{c}_{\mathrm{iy},}$ and $\mathrm{c}_{\mathrm{iz}}$ represent the stiffness and support damping of gear $i$ along the $x, y$, and $z$ directions $(i=1,2,3,4)$, respectively; $k_{13 x}, k_{13 y}, k_{13 z}, k_{j 13}, k_{24 x}$, $k_{24 y}, k_{24 z}$ and $k_{j 24}$ represent the stiffness influence factors of the $x, y, z$ directions and the twisting directions of both side gears, respectively; and $c_{13 x}, c_{13 y}, c_{13 z}, c_{j 13}, c_{24 x}, c_{24 y}$, $c_{24 z}$ and $c_{J 24}$ represent the damping coefficient of the $x_{\text {, }}$ $y, z$ directions and the torsional direction of both gears, respectively.

Several factors are responsible for gear vibration. This study mostly considered the mesh error excitation, timevarying stiffness excitation, and friction excitation.

Since the dynamic model considers the tooth surface friction and axial vibration, the model has 16 degrees of freedom and the system's generalized displacement array can be expressed as follows:

$\mathbf{X}=\left\{x_{1}, y_{1}, z_{1}, \theta_{1}, x_{2}, y_{2}, z_{2}, \theta_{2}, x_{3}, y_{3}, z_{3}, \theta_{3}, x_{4}, y_{4}, z_{4}, \theta_{4}\right\}^{T}$

Then, the relative displacements $\delta_{12}$ and $\delta_{34}$ of the double helical gear along the mesh line can be expressed as

$$
\left\{\begin{array}{l}
\delta_{12}=\left(y_{1}+r_{b 1} \theta_{1}-y_{2}+r_{b 2} \theta_{2}\right) \cos \beta_{b}-\left(z_{1}-z_{2}\right) \sin \beta_{b}-e_{1} \\
\delta_{34}=\left(y_{3}+r_{b 3} \theta_{3}-y_{4}+r_{b 4} \theta_{4}\right) \cos \beta_{b}+\left(z_{3}-z_{4}\right) \sin \beta_{b}-e_{2}
\end{array}\right.
$$

In the above formula, $r_{b 1}, r_{b 2}, r_{b 3}$, and $r_{b 4}$ are the base radii of each gear, while $e_{1}$ and $e_{2}$ are the gear meshing errors. According to the gear manufacturing accuracy level, the error is expressed as a simple harmonic function [17].

$e(t)=e_{a} \cos (\omega t+\varphi)$

where $e_{a}$ is the meshing error amplitude, $\omega$ is the gear mesh engagement frequency in rad/s, and $\varphi$ is the meshing phase angle.

Therefore, the elastic meshing force $\mathrm{F}_{\mathrm{km}}^{\mathrm{l}}, \mathrm{F}_{\mathrm{km}}^{\mathrm{r}}$ and the viscous meshing force $\mathrm{F}_{\mathrm{cm}}^{\mathrm{l}}, \mathrm{F}_{\mathrm{km}}^{\mathrm{r}}$ of the left and right gear pairs can be expressed as

$\begin{cases}F_{k m}^{l}=k_{m}^{l} \delta_{12} & F_{k m}^{r}=k_{m}^{r} \delta_{34} \\ F_{c m}^{l}=c_{m}^{l} \dot{\delta}_{12} & F_{c m}^{r}=c_{m}^{r} \dot{\delta}_{34}\end{cases}$

where $\mathrm{F}_{\mathrm{km}}^{\mathrm{l}}, \mathrm{F}_{\mathrm{km}}^{\mathrm{r}}, \mathrm{F}_{\mathrm{cm}}^{\mathrm{I}}$, and $\mathrm{F}_{\mathrm{cm}}^{\mathrm{r}}$ are, respectively, the meshing stiffness and meshing damping of the left and right gear pairs. The meshing stiffness value is obtained by TCA.

Based on the above analysis, the dynamic differential equation of the external meshing double helical gear pair is given by:

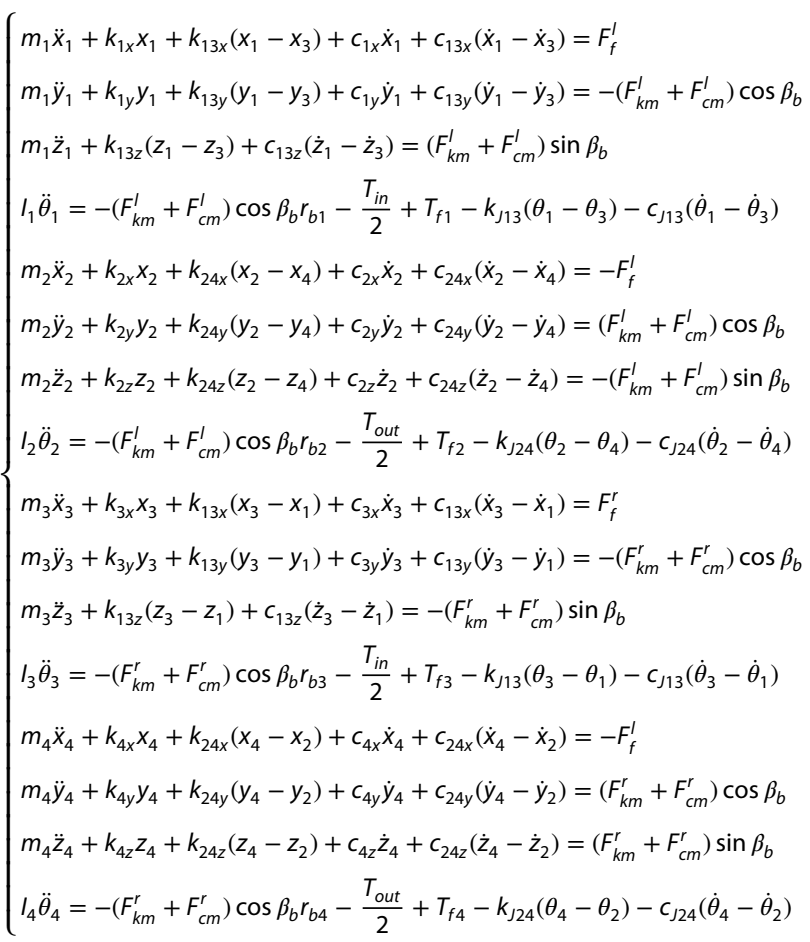

where $m_{i}$ and $l_{i}(i=1,2,3,4)$ are the mass and moment of inertia of gear $i$, respectively; $F_{f}^{\prime}$ and $F_{f}^{r}$ are the tooth surface friction forces of the left and right gear pairs, respectively; and $\mathrm{T}_{1}^{\mathrm{f}}, \mathrm{T}_{2}^{\mathrm{f}}, \mathrm{T}_{3}^{\mathrm{f}}$, and $\mathrm{T}_{4}^{\mathrm{f}}$ are the friction moments of the gear surface friction force on each gear. 
The mass matrix $M$, stiffness matrix $K$, damping matrix $\mathrm{C}$, and excitation force matrix $\mathrm{F}$ can be extracted using the above formula. Since the damping coefficient is difficult to determine, Rayleigh damping is used in this study. The Rayleigh damping coefficients $\alpha$ and $\beta$ are used as reference [32].

$\mathbf{C}=\alpha \mathbf{M}+\beta \mathbf{K}$

The differential equations can be arranged as a matrix:

$\mathbf{M} \ddot{\mathbf{X}}+\mathbf{K X}+\mathbf{C} \dot{\mathbf{X}}=\mathbf{F}$

After eliminating the displacement of the rigid body, the displacement and velocity vectors are obtained using the Runge-Kutta method and then inserted into Eq. (4) to determine the dynamic meshing force.

\subsection{Calculation of friction force and sliding friction power loss}

From the dynamic equation in Sect. 2.1, it can be observed that the tooth surface meshing force and friction force are unknown, while the tooth surface friction force and friction coefficient are all dependent on the meshing force. When applying the Runge-Kutta method, the general processing method is to use the meshing force obtained from the solution of the previous loop to calculate the tooth surface friction force. The friction force is then used for the current cycle calculation in an iterative process until the two curves achieve reasonable stability.

Owing to the huge amount of finite element calculations, the meshing implemented for TCA should not be too dense. Therefore, the step size of the Runge-Kutta method will be much smaller than the step length of TCA regardless of whether a fixed-step or variable-step solver is used. To solve the data mismatch problem, it is considered that the load distribution in the vicinity of the discrete contact line has the same tendency since the discrete contact line load distribution curve is non-dimensionalized. According to the load of the current meshing position and the length of the contact line, the dimensionless load distribution curve is dimensioned such that the load distribution curve of the current meshing position is determined.

Assuming that the total meshing force is $\mathrm{F}_{\mathrm{m}}$ at a certain time $t$, the expression for the friction force $F s$ on a single contact line is given as:

$F_{s}(t)=\int_{l} \operatorname{sgn}\left[v_{s}(u, t)\right] \mu(u, t) q_{L}(t) q_{C}(u, t) F_{m} d u$

where $q_{L}(t)$ is the tooth-to-tooth load distribution rate at time $t ; q_{c}(u, t)$ is the tooth surface load distribution function obtained from the loaded TCA (LTCA) model; $u$ is the positional argument, which indicates the length from the starting point of the contact line; $I$ is the contact line length of the current meshing position; $v_{s}(u, t)$ is the relative sliding speed of the tooth surface; and $\mu(\mathrm{u}, \mathrm{t})$ is the friction coefficient. The above parameters are all functions of the position and time. The friction coefficient model uses the friction coefficient calculation model proposed by Xu [4] based on the theory of elastohydrodynamic lubrication. The term sgn() is a signum function whose expression is:

$\operatorname{sgn}(x)= \begin{cases}1 & x>0 \\ 0 & x=0 \\ -1 & x<0\end{cases}$

The friction torques of the single contact line on the driving wheel and the driven wheel $\operatorname{are}_{\mathrm{s} 1}$ and $\mathrm{T}_{\mathrm{s} 2}$, respectively, and are given as:

$\left\{\begin{array}{l}T_{s 1}(t)=\int_{l} \operatorname{sgn}\left[v_{s}(u, t)\right] \mu(u, t) q_{L}(t) q_{C}(u, t) F_{m} R_{t 1}(u, t) d u \\ T_{s 2}(t)=\int_{l} \operatorname{sgn}\left[v_{s}(u, t)\right] \mu(u, t) q_{L}(t) q_{C}(u, t) F_{m} R_{t 2}(u, t) d u\end{array}\right.$

where $R_{t 1}(u, t)$ and $R_{t 2}(u, t)$ are, respectively, the force arm of the friction force on the driving wheel and the driven wheel at any position of the contact line at time $t$.

If the friction force curves and friction torque curves of adjacent contact lines differ in time by a meshing period $T_{m^{\prime}}$ then the total friction force and friction torque of the driving wheel and the driven wheel are:

$\left\{\begin{array}{l}F_{f}=\sum_{i=-N}^{N} F_{s}\left(t+i T_{m}\right) \\ T_{f 1}=\sum_{i=-N}^{N} T_{s 1}\left(t+i T_{m}\right) \\ T_{f 2}=\sum_{i=-N}^{N} T_{s 2}\left(t+i T_{m}\right)\end{array}\right.$

where $\mathrm{N}$ is the maximum number of teeth engaged in meshing at the same time.

The friction force at each point of the contact line and the relative sliding speed are different. The instantaneous power loss calculation integrates the power loss at each point along the contact line. The formula for the power loss of a single contact line is as follows:

$P_{s}(t)=\int_{I} \mu(u, t) q_{L}(t) q_{C}(u, t) F_{m} v_{s}(u, t) d u$

Similarly, the total power loss at any time $t$ is: 
Table 1 Double helical gear parameters

\begin{tabular}{llllllll}
\hline z1 & z2 & Modulus $(\mathrm{mm})$ & Normal pressure angle $\left(^{\circ}\right)$ & Helix angle $\left(^{\circ}\right)$ & Tooth width $(\mathrm{mm})$ & Rotating speed $(\mathrm{r} / \mathrm{min})$ & Input power $(\mathrm{kW})$ \\
\hline 45 & 43 & 3.5 & 22.5 & 28 & 60 & 7200 & 4500
\end{tabular}

$P_{f}=\sum_{i=-N}^{N} P_{s}\left(t+i T_{m}\right)$

The average power loss is obtained by integrating the instantaneous power loss along the time axis and then averaging as given below:

$P=\frac{1}{T_{m}} \int_{t_{1}}^{t_{1}+T_{m}} P_{f}(t) d t$

The average meshing efficiency can be expressed as:

$\eta=\left(1-\frac{P}{P_{\text {in }}}\right) \times 100 \%$

where $P_{\text {in }}$ is the input power.

\section{Sensitivity analysis of meshing efficiency of double helical gear parameters}

Gear transmission efficiency is one of the important parameters that determine the quality of gear transmission. High-efficiency gear pairs improve energy efficiency, reduce power loss, and heat generation. Particularly in the aviation sector, improving the transmission efficiency of a gear pair is of great significance to improve the output power, increase the takeoff weight, and reduce the size of the components.

In this study, an external meshing double helical gear in a gearbox was selected for investigation. The parameters are listed in Table 1. The operating conditions and design parameters were varied using the parameters in Table 1, and the influence of the parameters on the meshing efficiency was examined.

\subsection{Effect of input power, rotating speed, and transmission torque on efficiency}

The gear meshing error, time-varying stiffness, tooth surface friction, and so forth will lead to vibration in the gear system and dynamic loading, which affect the gear transmission efficiency. At different input power and speed conditions, the gears have different vibration conditions; thus, it is necessary to investigate the influence of the input power, speed, and torque on the transmission efficiency.

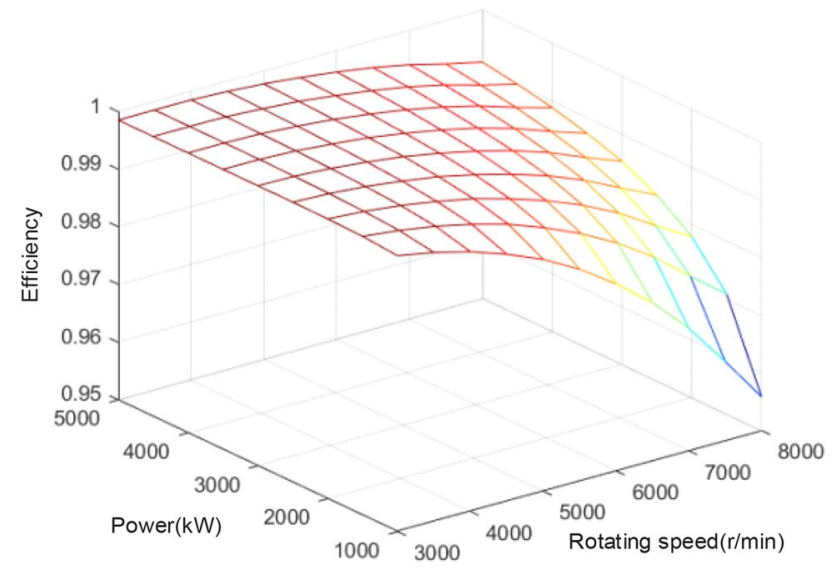

Fig. 2 Efficiency at different input power and speed

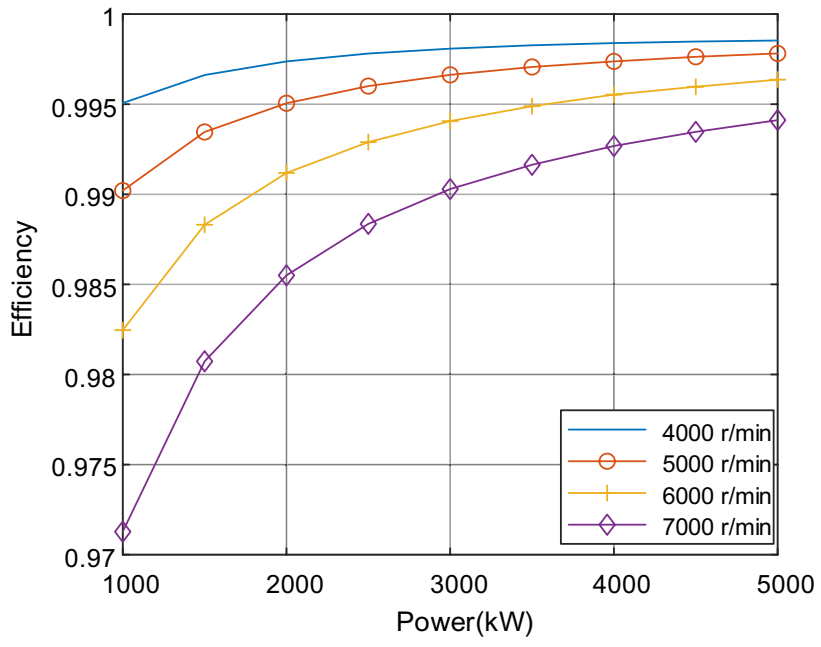

Fig. 3 Efficiency at different input power with constant speed

The stiffness of the support is adjusted during the calculation to avoid resonance.

Figure 2 shows the transmission efficiency variation calculated at input power condition of $1000-5000 \mathrm{~kW}$ and speed of $3000-8000 \mathrm{r} / \mathrm{min}$. The efficiency distribution under constant speed, constant torque, and constant power is shown in Figs. 3, 4 and 5, respectively.

It can be observed in Fig. 3 that the efficiency increases with the increase in the input power under constant rotation speed. According to the friction coefficient calculation model proposed by $\mathrm{Xu}$ [4] based on the 


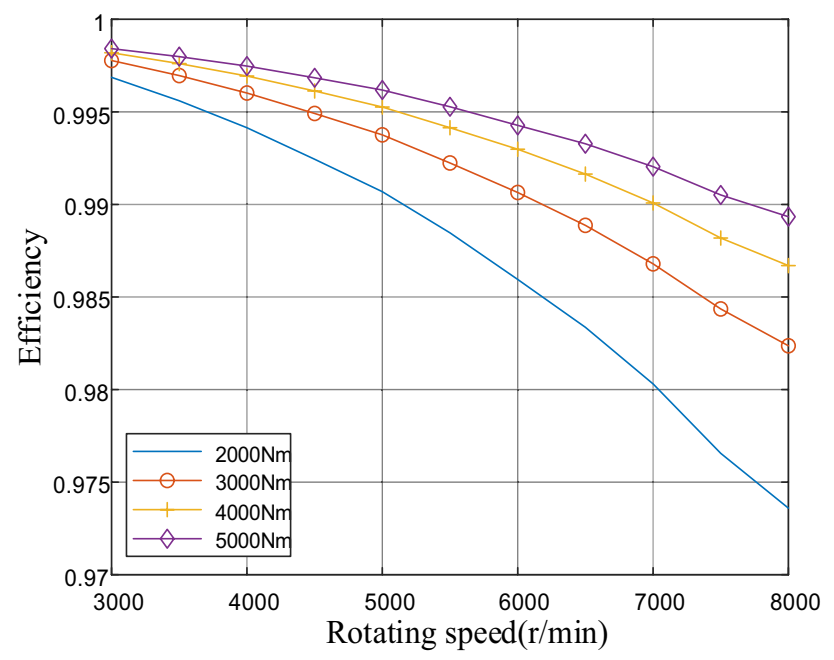

Fig. 4 Efficiency at different speed with constant torque

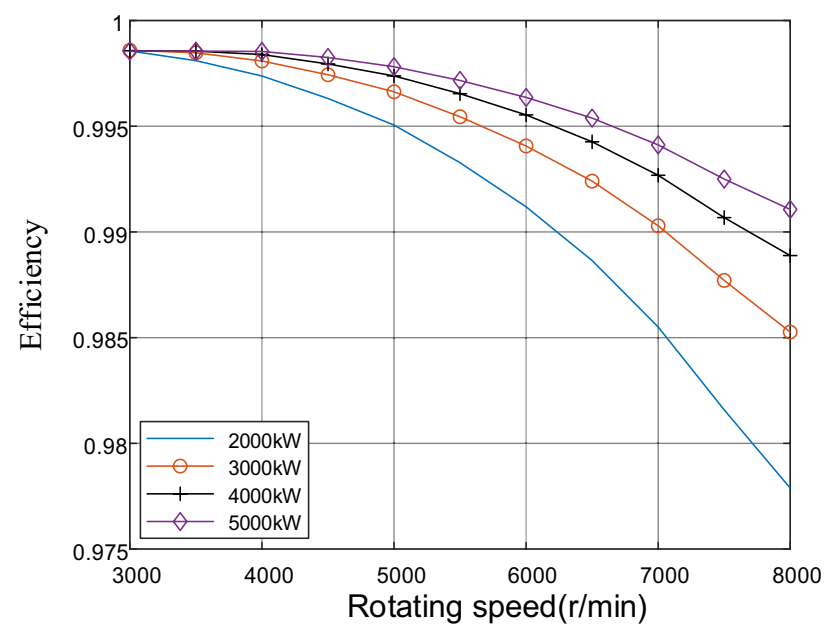

Fig. 5 Efficiency at different speed with constant input power

theory of elastohydrodynamic lubrication, as the input power increases, the unit normal load increases, and the friction coefficient increases, and then decreases, as shown in Fig. 6. The normal load of the working state is $0.5-5 \times 10-3 \mathrm{GN} / \mathrm{m}$, which falls to the right of the highest point of the curve. Therefore, at a constant rotational speed, the efficiency increases as the input power increases. In Fig. 4, under constant torque conditions, the efficiency decreases as the speed increases. This is because as the rotation speed increases, the entrainment velocity increases, and the friction coefficient increases. Figure 7 shows the friction coefficient curve at different entrainment velocities. In addition, as the rotational speed increases, the dynamic load due to the vibration increases, resulting in reduced efficiency. When the input power is constant, the tooth surface load decreases with

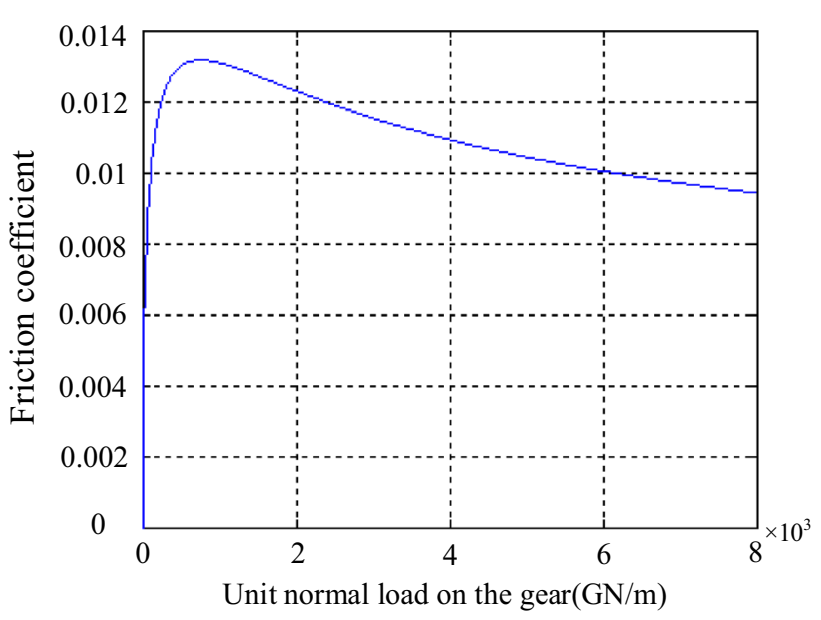

Fig. 6 Influence of normal load per unit of the gear on friction coefficient

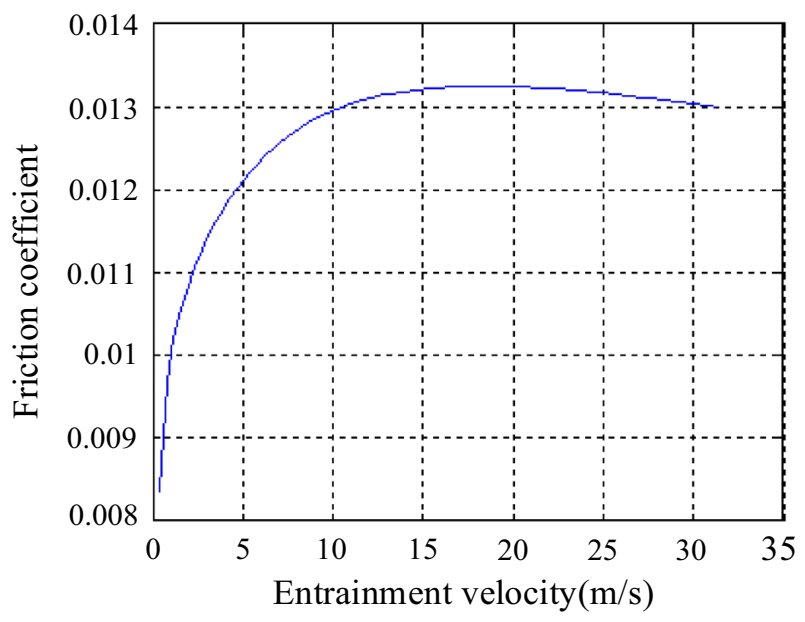

Fig. 7 Influence of entrainment velocity on friction coefficient

the increase in the rotational speed. With comprehensive consideration of all factors, the efficiency is reduced, as shown in Fig. 5.

\subsection{Effect of helix angle on efficiency}

The helix angle is an important characteristic parameter of the helical gear, and it is also the main factor affecting the magnitude of the axial force and the change of the contact line. When the input power is $4500 \mathrm{~kW}$ and the rotation speed is $7200 \mathrm{r} / \mathrm{min}$, the efficiency distribution with helix angle in the range of $5-35^{\circ}$ is shown in Fig. 8 . It can be observed from the figure that as the helix angle increases, the overall efficiency gradually decreases. For helix angle in the range of $10-25^{\circ}$, the decrease in the efficiency is small, and at helix angles greater than $25^{\circ}$, the efficiency 


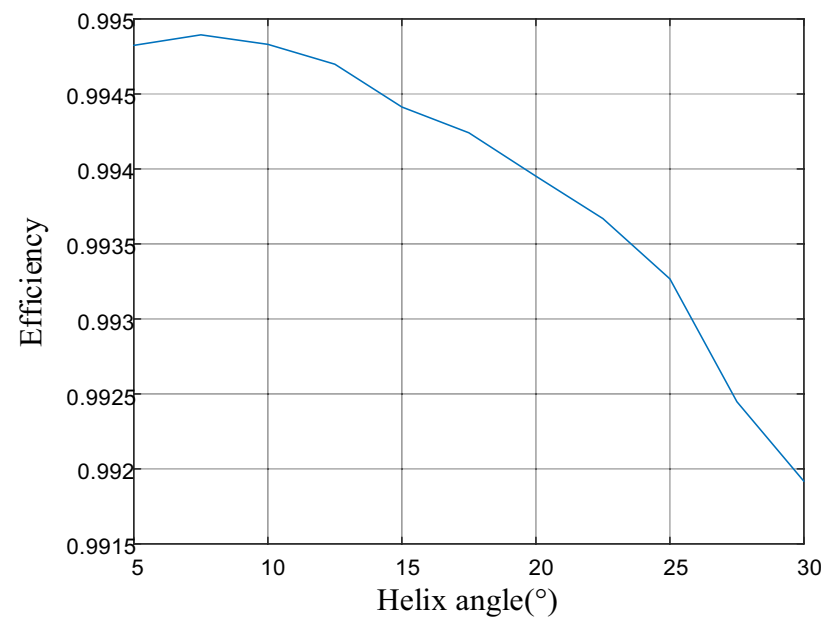

Fig. 8 Influence of helix angle on transmission efficiency

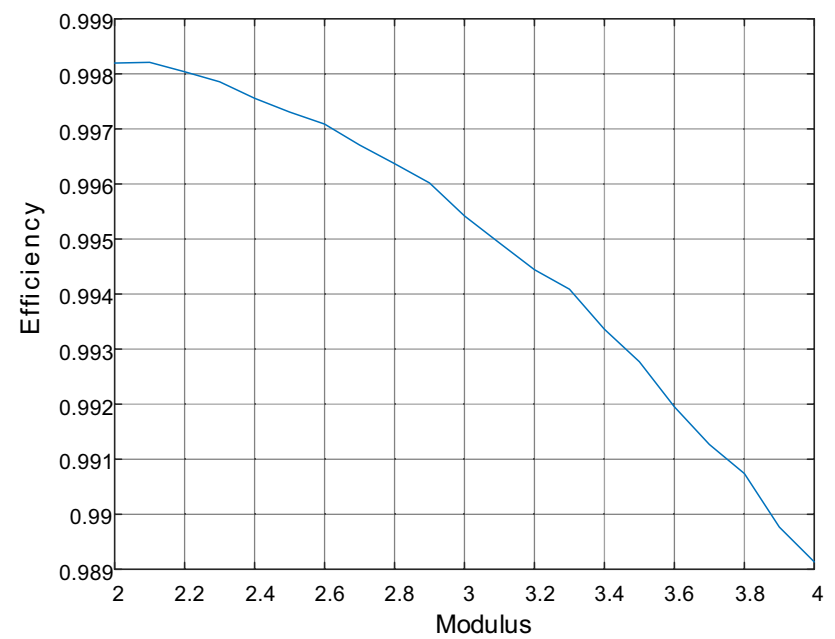

Fig. 9 Influence of modulus on transmission efficiency

drops sharply. At constant input power, the formula $F_{n}=F_{t} /$ $\cos \beta$ indicates that the introduction of the helix angle generates additional axial force, which increases the normal load of the tooth surface and further increases the power loss.

\subsection{Effect of modulus on efficiency}

Different moduli directly affect various geometric parameters of the gear, which in turn affect the gear's transmission efficiency. Figure 9 shows the efficiency distribution and modulus in the range of 2-4.5 at input power of $4500 \mathrm{~kW}$ and rotation speed of $7200 \mathrm{r} / \mathrm{min}$.

As can be observed in Fig. 9, as the modulus increases, the transmission efficiency decreases. This is because the overall size of the gear increases as the modulus increases,

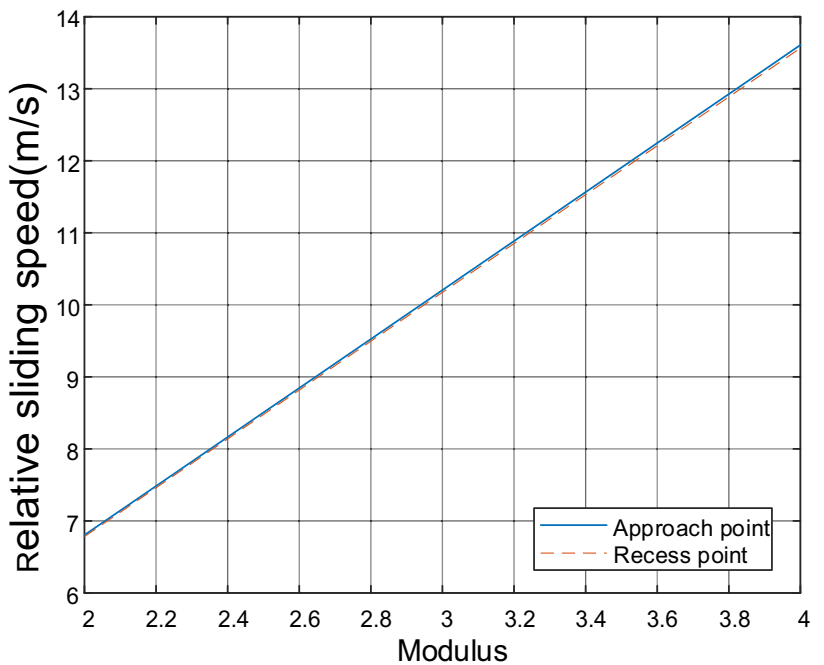

Fig. 10 Influence of modulus on relative sliding speed

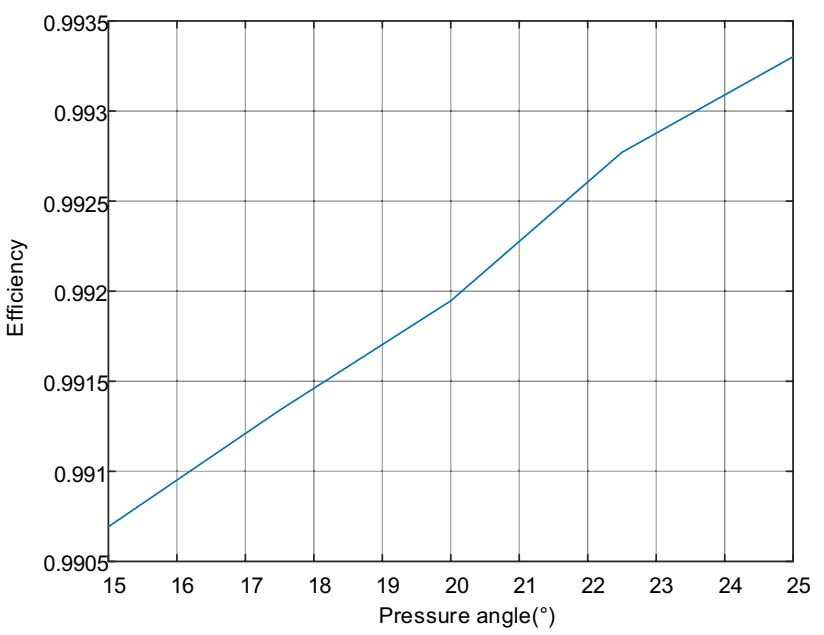

Fig. 11 Influence of pressure angle on transmission efficiency

when other parameters remain constant. At the same speed, the linear velocity of the gear increases and the friction power loss increases. Figure 10 shows the linear relationship between the relative sliding speed and the modulus at the meshing and recess point.

\subsection{Effect of pressure angle on transmission efficiency}

Figure 11 shows the efficiency distribution with pressure angle in the range of $15-25^{\circ}$ when the input power is $4500 \mathrm{~kW}$ and the rotation speed is $7200 \mathrm{r} / \mathrm{min}$. The transmission efficiency increases with the increase in the pressure angle because as the pressure angle increases, the width of the meshing surface becomes smaller, the relative sliding speed of the meshing and recess point becomes 
smaller, and the friction power loss decreases. Figure 12 shows the linear relationship between the relative sliding speed and the pressure angle at the meshing and recess point.

\subsection{Effect of tooth widths on transmission efficiency}

Figure 13 shows the efficiency distribution at different effective tooth widths when the input power is $4500 \mathrm{~kW}$ and the rotation speed is $7200 \mathrm{r} / \mathrm{min}$. The transmission efficiency increases with the increase in the effective tooth width. The main reason is that as the effective tooth width increases, the unit normal load of the gear decreases, and the friction coefficient increases, resulting in increased friction loss. The relationship between the unit normal load of the gear and the friction coefficient is shown in Fig. 6.

\subsection{Effect of modification coefficient on transmission efficiency}

Figure 14 shows the efficiency distribution with modification coefficient in the range of -0.5 to 0.5 when the input power is $4500 \mathrm{~kW}$ and the rotation speed is $7200 \mathrm{r} /$ $\mathrm{min}$. It can be observed from the figure that the transmission efficiency is maximum when the modification coefficient is approximately zero. As shown in Fig. 15, when the modification coefficient is close to 0 , the relative sliding speeds of the meshing and recess point are equal. For instance, during positive modification, as the modification coefficient increases, the meshing plane as a whole shift, the relative sliding speed of the meshing point decreases, and the relative sliding speed of the recess point increases. Compared with the modification

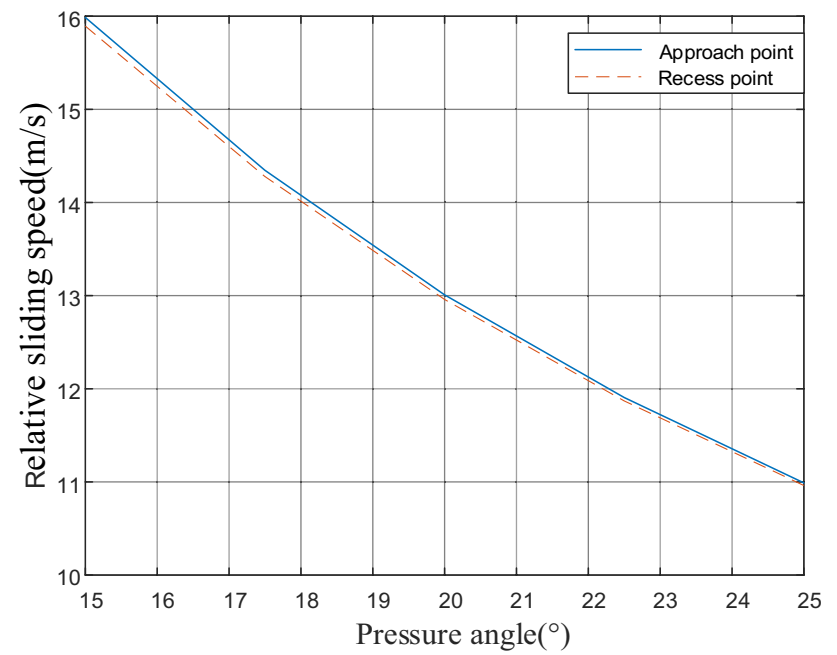

Fig. 12 Influence of pressure angle on relative sliding speed

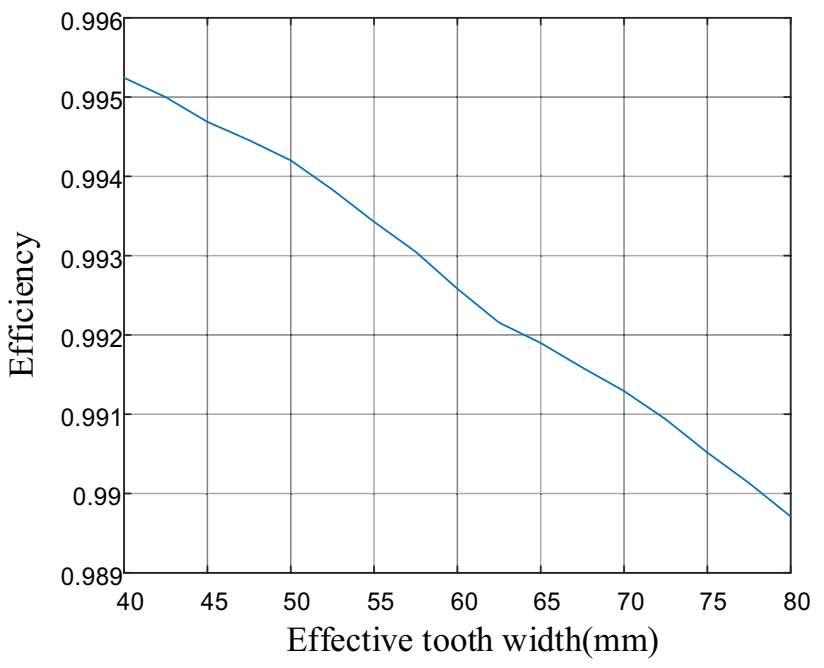

Fig. 13 Influence of effective tooth width on transmission efficiency

coefficient of 0 , the actual friction power loss increased so that the transmission efficiency is reduced.

In summary, the influence of relevant parameters on transmission efficiency is shown in Table 2 below. Moreover, it could be found that the influence of design parameters on meshing efficiency is followed as modulus, pressure angle $>$ helical angle, tooth widths.

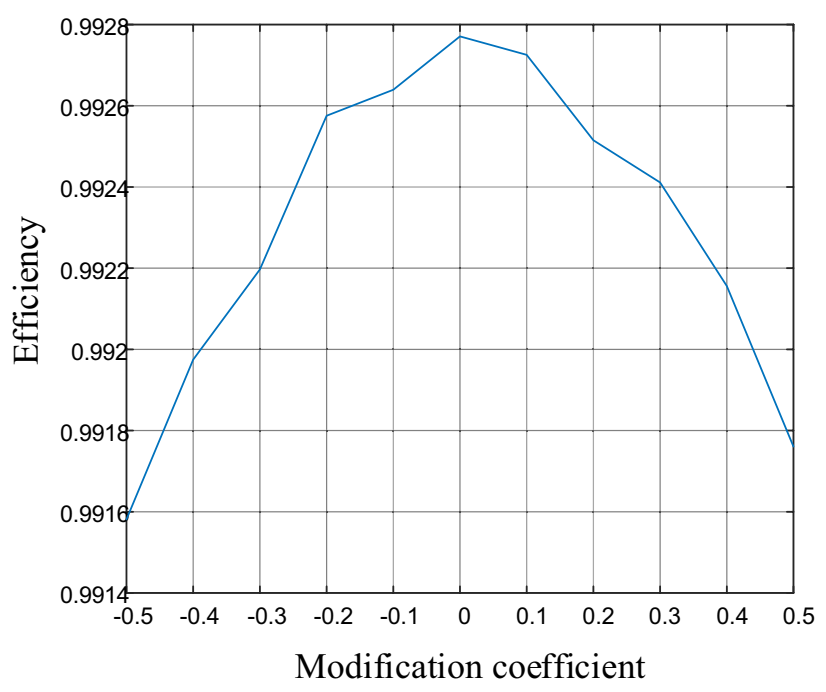

Fig. 14 Influence of modification coefficient on transmission efficiency 


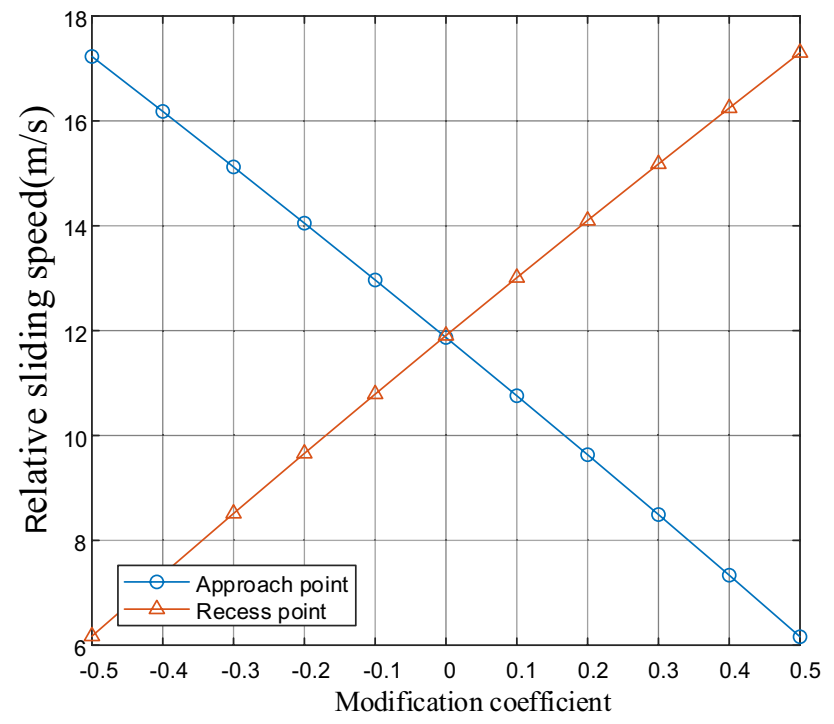

Fig. 15 Influence of modification coefficient on relative sliding speed

\section{Optimization design method and discussion}

At present, General Electric (GE), Pratt \& Whitney, Pratt \& Whitney's PW1000G geared fan engine(GTF), known as the advanced clean power, has become the standard for the next generation civil aero engines. The transmission system of the engine adopts star gear transmission structure, which is composed of a central gear driven by a low pressure turbine, five star gears, and one outer ring gear connected with the fan. In view of the above background, it is of great significance to study the power loss of herring tooth star gear transmission system, analyze the influence of various parameters on transmission efficiency, and summarize the design method of high efficiency herring gear for improving the efficiency of GTF engine.

\subsection{Gear bending strength calculation}

In addition to the modification coefficient, the gear transmission efficiency is a monotonically increasing or monotonically decreasing function of the design parameters. Therefore, it is necessary to introduce appropriate constraints so that parameter optimization is meaningful. From the above analysis, the gear transmission efficiency is closely related to the bearing capacity of the gears. This study proposes the concept of parameter optimization under constant bending strength conditions, and introduces the gear bending strength as a constraint condition. The parameters are optimized without weakening the gear strength taking the bearing capacity of the gears into account, or the allowable bending stress of the gear is determined. When optimizing the parameters, the strength always meets the design requirements.

When calculating the bending strength of the gear, the tooth root stress is calculated according to HB/Z 84.3-1984. The basic formula is as follows:

$\sigma_{F 0}=\frac{F_{t}}{b m_{n}} Y_{F} \cdot Y_{S} \cdot Y_{\beta}$

In the above formula:

$\mathrm{F}_{\mathrm{t}} \quad$ Nominal tangential force, $\mathrm{N}$;

b Working tooth width, $\mathrm{mm}$;

$\mathrm{mn}$ Normal modulus, $\mathrm{mm}$;

$\mathrm{Y}_{\mathrm{F}} \quad$ Tooth profile coefficient when the load acts on the upper boundary of the single tooth meshing area;

$\mathrm{Y}_{S} \quad$ Stress correction factor when the load acts on the upper boundary of the single tooth meshing area;

$\mathrm{Y}_{\beta} \quad$ Helix angle coefficient.

The calculation result in this example is:

$\sigma_{F 0}=306.36 \mathrm{MPa}$
Table 2 The influence of various parameters on transmission efficiency

\begin{tabular}{lll}
\hline Modulus & Parameter & Transmission efficiency \\
\hline 1 & Input power $\uparrow$ & $\uparrow$ \\
& Rotating speed $\uparrow$ & $\downarrow$ \\
& Transmission torque $\uparrow$ & $\downarrow$ \\
2 & Helical angle $\uparrow$ & $\downarrow$ \\
3 & Modulus $\uparrow$ & $\downarrow$ \\
4 & Pressure angle $\uparrow$ & $\uparrow$ \\
5 & Tooth widths $\uparrow$ & $\downarrow$ \\
6 & Modification coefficient & Efficiency is maximum when the modi- \\
& & fication coefficient is approximately \\
& & zero \\
\hline
\end{tabular}




\subsection{Equal bending strength optimization}

Feasible domain range:

Modulus: The available moduli according to GB 13571978 are $3.25,3.5,3.75$;

Pressure angle: The available pressure angles according to $\mathrm{GB} / \mathrm{T} 1356-1988$ are $20^{\circ}, 22.5^{\circ}, 25^{\circ}$;

Helix angle: Range $20-30^{\circ}$;

Tooth width: To ensure that the bending strength of the gears is the same, that is, the bending stress of the tooth root remains $306.36 \mathrm{MPa}$ under the same load, numerical calculations are used to determine the corresponding tooth width values at the different parameters indicated above. Figures 16,17 and 18 show the tooth width values corresponding to different pressure angles, moduli, and helix angles. It can be observed from the figures that as the helix angle increases, the tooth width gradually decreases mainly because the increase in the helix angle improves the degree of gear coincidence, and the bearing capacity of the gear is also improved. For a single pair of gears, the increase in the pressure angle is beneficial in order to improve the bending strength of the gears. However, owing to the increase in the pressure angle, the transverse contact ratio will be reduced. Under the combined effect of both, the pressure angle has a small influence on the bearing capacity of the entire meshing pair.

The meshing efficiency under various design parameters was calculated and the results are shown in Figs. 19,

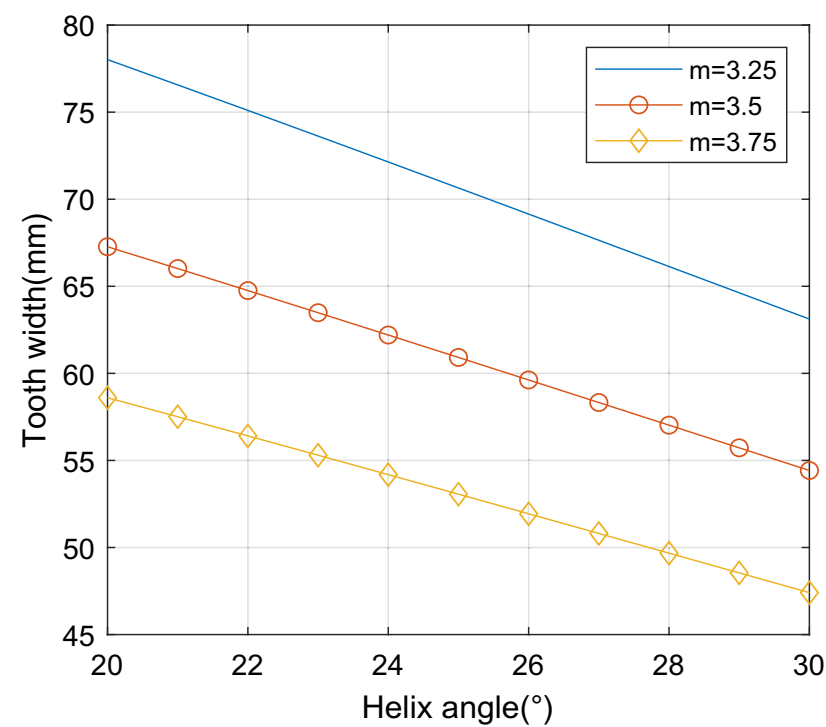

Fig. 16 Tooth width value of different modulus and helix angle at equal bending strength of the teeth and pressure angle of $20^{\circ}$

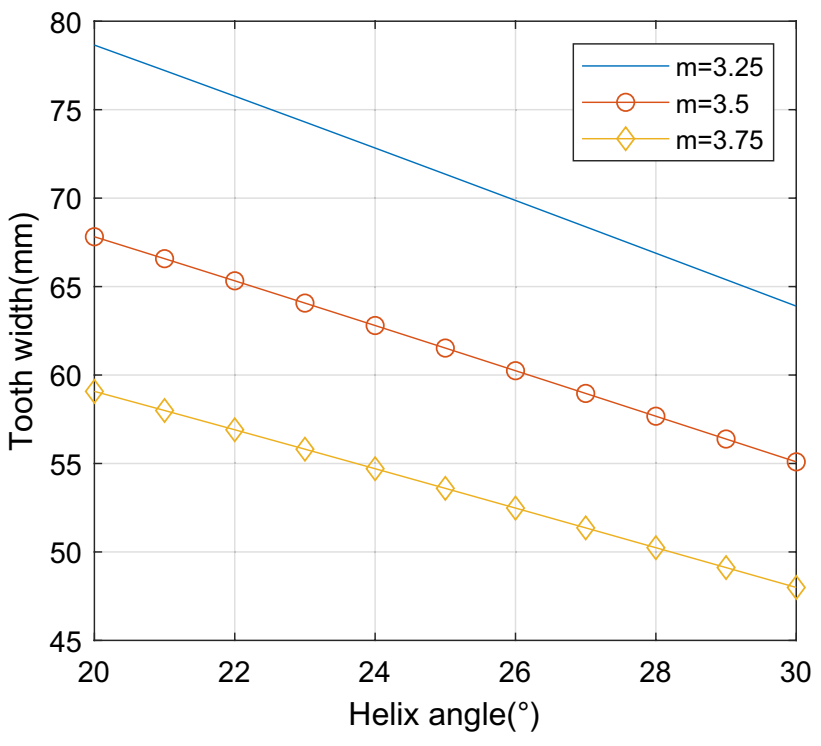

Fig. 17 Tooth width value of different modulus and helix angle at equal bending strength of the teeth and pressure angle of $22.5^{\circ}$

20 and 21. It can be observed from the figures that under the condition of equal bending strength, the influence of various design parameters on the gear meshing efficiency is slightly different from that of the previous single factor analysis.

(1) Under the conditions of equal gear bending strength, the meshing efficiency values obtained at different design parameters have a certain span, indicating that this method has room for optimization. In this

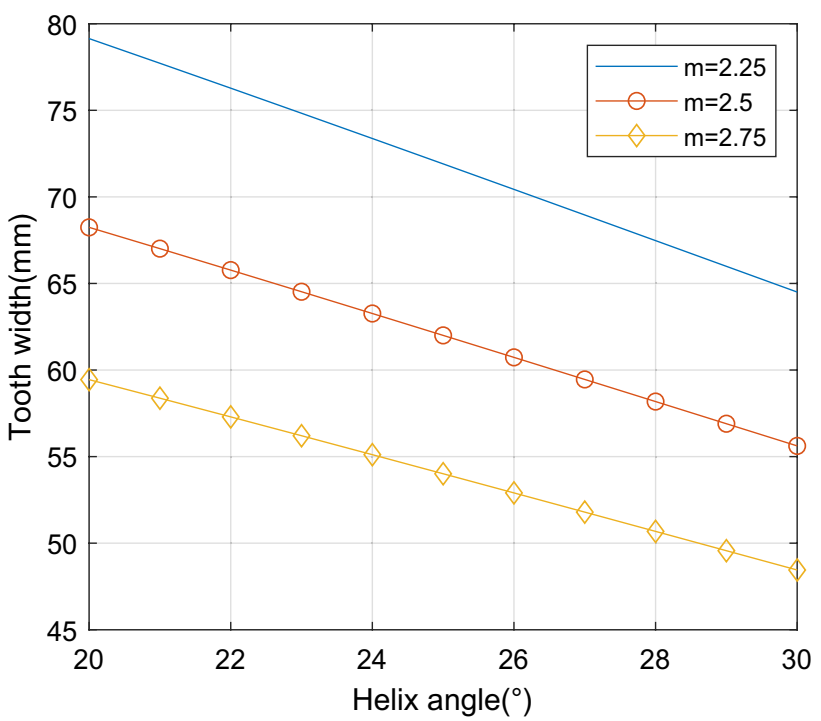

Fig. 18 Tooth width value of different modulus and helix angle at equal bending strength of the teeth and pressure angle of $25^{\circ}$ 


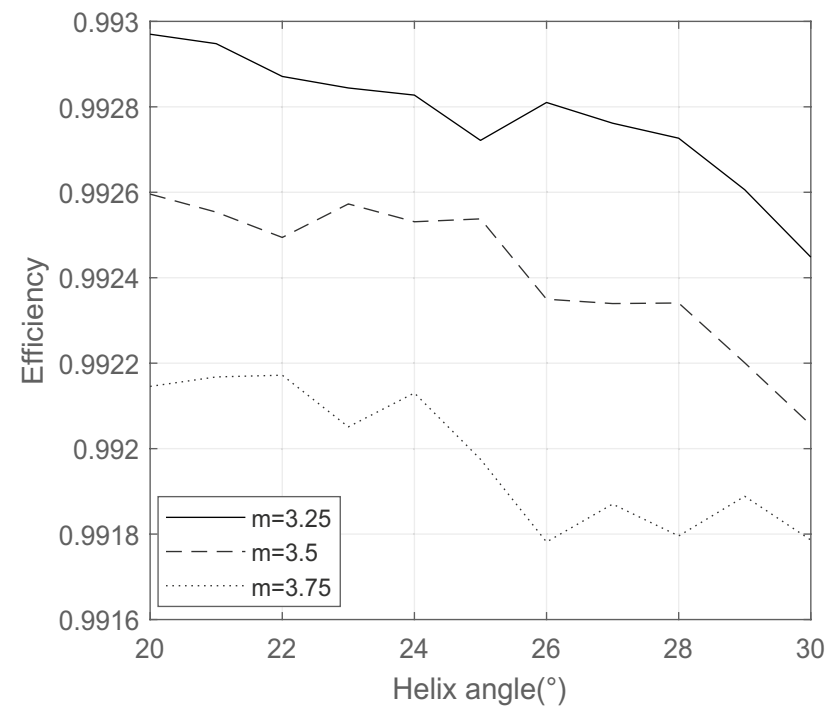

Fig. 19 Efficiency of different modulus and helix angle at equal bending strength of the teeth and pressure angle of $20^{\circ}$

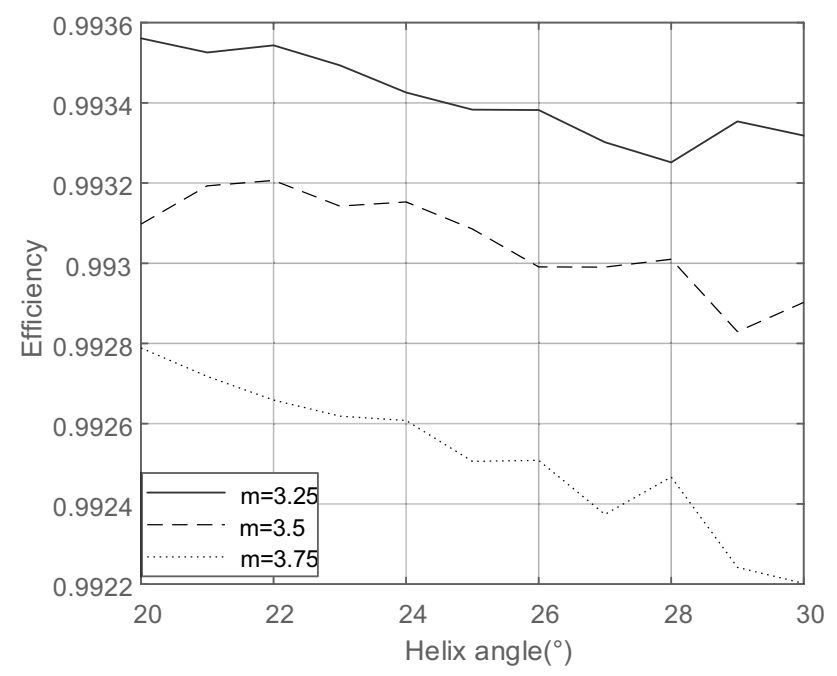

Fig. 20 Efficiency of different modulus and helix angle at equal bending strength of the teeth and pressure angle of $22.5^{\circ}$

case, the minimum meshing efficiency is 0.9918 and the maximum meshing efficiency is 0.9943 , a difference of 0.002 .

(2) The meshing efficiency varies gradually with the helix angle under the condition of equal gear bending strength. This is because as the helix angle varies, the tooth width also varies, and the introduction of the tooth width plays a role in compensating for the suppression. Based on this, it can be observed that the helix angle and the tooth width have almost the same influence on the meshing efficiency.

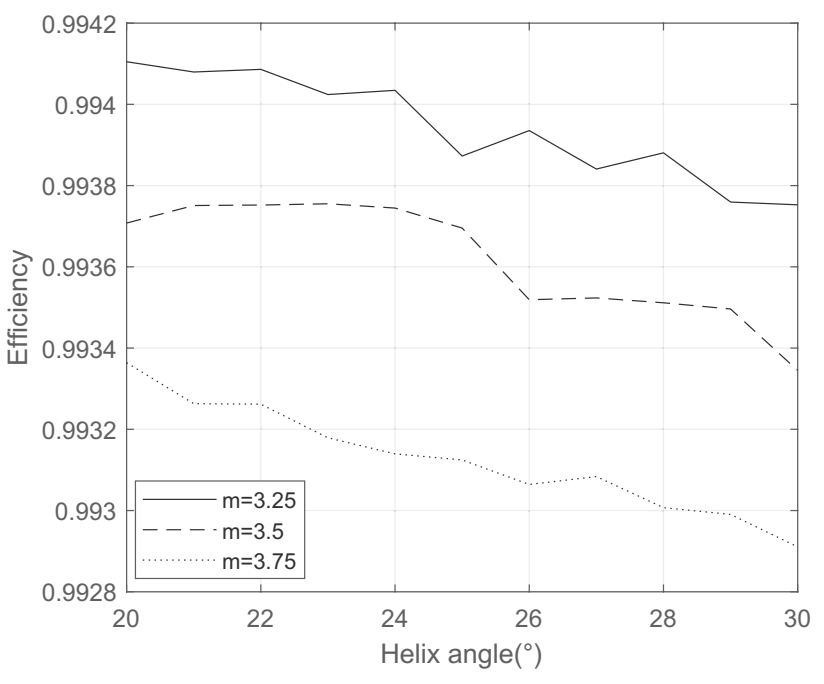

Fig. 21 Efficiency of different modulus and helix angle at equal bending strength of the teeth and pressure angle of $25^{\circ}$

(3) Although the introduction of the tooth width plays a role in compensating for the suppression, the trend of the effect of modulus and pressure angle on efficiency is basically the same as the trend when analyzing the two separately, and the effect of modulus on efficiency is even more obvious.

(4) In summary, we can determine the influence weight of each parameter on the efficiency: modulus, pressure angle $>$ helix angle, tooth width.

The above results indicate that if the modulus and pressure angle do not change, the helix angle can be taken as $26^{\circ}$ as shown in Fig. 20, and the corresponding tooth width is obtained by querying Fig. 17; the tooth width is determined as $60 \mathrm{~mm}$. Since the efficiency (helix angle $=28^{\circ}$ ) at the original parameters is close to the maximum efficiency point, the optimization space is not large.

If the modulus and pressure angle change, the modulus and pressure angle can be selected as 3.25 and $25^{\circ}$, respectively according to Fig. 21 . Since the meshing efficiency tends to be stable when the helix angle is in the range of $20-24^{\circ}$, it is preferable to select a large helix angle; on the one hand, shock vibration can be reduced, and on the other hand, the tooth width and the structural weight can be reduced. At the same time, to ensure that the center distance is an integer, the helix angle is adjusted to $23.85^{\circ}$, corresponding to an effective tooth width value of $73 \mathrm{~mm}$. After optimizing the parameters, the meshing efficiency increased from 99.3465 to $99.3574 \%$, an increase of $0.0109 \%$ (Table 3 ).

From the above analysis, it can be observed that since the modulus has the greatest influence on the efficiency, 
Table 3 Optimization comparison of helix angle parameters

\begin{tabular}{llll}
\hline Modulus & $\begin{array}{l}\text { Pressure angle } \\
\left({ }^{\circ}\right)\end{array}$ & Helix angle $\left(^{\circ}\right)$ & $\begin{array}{l}\text { Meshing } \\
\text { efficiency } \\
(\%)\end{array}$ \\
\hline 3.25 & 23 & 26 & 99.3465 \\
3.25 & 23 & 23.85 & 99.3574 \\
\hline
\end{tabular}

the use of a small modulus to increase the effective tooth width is preferred when applying equal gear bending strength optimization. To avoid gear eccentric load, the increase in the tooth width will be accompanied by an increase in the precision of the gear. Therefore, in the actual optimization process, the problems of gear precision and the technical aspects should also be considered.

\section{Conclusion}

After establishing the double helical gear dynamics model, solving method, analyzing the influence of gear design parameters and proposing the optimization scheme, the following conclusions could be drawn:

- The gear meshing efficiency increases with the decrease in the modulus, helix angle, and effective tooth width; however, the reduction of the modulus, helix angle, and effective tooth width will weaken the bearing capacity of the gear. Under the condition that the speed is determined, the meshing efficiency increases with the input power. Therefore, under the premise of satisfying the safety factor in the design of the gear parameters, the gear strength can be appropriately reduced or the input power can be increased so that the bearing capacity of the gear can be fully utilized.

- Under the condition of equal gear bending strength, the influence weight of each parameter on the efficiency is modulus, pressure angle $>$ helix angle, tooth width. For the optimization, small moduli and large pressure angles can be selected. Aerospace gears are often used with $22.5^{\circ}$ or $25^{\circ}$ pressure angles.

- Considering the bending strength of gears as a constraint condition, the bearing capacity of gears should be simultaneously taken into account when the parameters are optimized, which makes the optimization of the parameters practicable. The calculation results show that this method has a certain optimization space.

The actual engine power loss calculation is essential to consider the casing, the drive system structure, gear lubrication for meshing power loss in future research, more profound work would be taken into account to gradually form a more complete power loss calculation model of herring tooth star gear transmission system.

Author contributions Conceptualization, F.L.; methodology, X.C. and W.L.; simulation, F.L., X.C. and W.L.; data curation, F.L.; writing-originaldraft preparation, X.C. and W.L.; writing - review and editing, F.L. and X.C.; supervision, F.L. and W.L.; project administration, F.L.; funding acquisition, F.L. All authors have read and agreed to thepublished version of the manuscript.

Funding This research was funded by the Aeronautical Science Foundation of China, grant number ASFC-20182852027.

Data availability statement No new data were created or analyzed in this study. Data sharing is not applicable to this article.

\section{Declarations}

Conflicts of Interest The authors declare no conflict of interest.

Open Access This article is licensed under a Creative Commons Attribution 4.0 International License, which permits use, sharing, adaptation, distribution and reproduction in any medium or format, as long as you give appropriate credit to the original author(s) and the source, provide a link to the Creative Commons licence, and indicate if changes were made. The images or other third party material in this article are included in the article's Creative Commons licence, unless indicated otherwise in a credit line to the material. If material is not included in the article's Creative Commons licence and your intended use is not permitted by statutory regulation or exceeds the permitted use, you will need to obtain permission directly from the copyright holder. To view a copy of this licence, visit http://creativecommons. org/licenses/by/4.0/.

\section{References}

1. Marques PMT, Martins RC, Seabra JHO (2016) Gear dynamics and power loss. J Artic 97:400

2. Buckingham (1949) Analytical mechanics of gear. Dover, New York, pp 406-407

3. Benedict GH, Kelley BW (1961) Instantaneous coefficients of gear tooth friction. ASLE Trans 4:59-70

4. $\mathrm{Xu} \mathrm{H} \mathrm{(2005)} \mathrm{Development} \mathrm{of} \mathrm{a} \mathrm{generalized} \mathrm{mechanical} \mathrm{efficiency}$ prediction methodology for gear pairs. ProQuest Dissertations Publishing

5. Liang D, Li W, Chen B (2020) Mathematical model and meshing analysis of internal meshing gear transmission with curve element. J Mech Sci Technol 34:5155-5166

6. Marimuthu P, Muthuveerappan G (2016) Design of asymmetric normal contact ratio spur gear drive through direct design to enhance the load carrying capacity. Mech Mach Theory 22-34

7. Kolivand M, Li S, Kahraman A (2010) Prediction of mechanical gear mesh efficiency of hypoid gear pairs. Mech Mach Theory 45(11):1568-1582

8. Lin C, Liu W, Xing Q, Xia X, Tang P (2019) Calculation and analysis of meshing efficiency of composite motion of the curve-face gear pair. Trans Can Soc Mech Eng 43(3):431-441 
9. Liu XL, Liang WH, Cui YH, Liu K (2013) Research on influence of intertooth space confriction to transmission efficiency under EHL. Adv Mater Res 605-607:1158-1163

10. Chen X, Lu Z (2013) Modeling of dynamic efficiency of spur gear pairs based on elastohydrodynamic lubrication and its validation. Tóngjì Dàxué Xuébào (1980) 415:773-778

11. Simon VV (2019) Improved mixed elastohydrodynamic lubrication of hypoid gears by the optimization of manufacture parameters. Wear 438-439

12. Wang $R$ et al (2019) Meshing efficiency analysis of modified cycloidal gear used in the RV reducer. Tribol Trans 62(3):337-349

13. Liu Y, Song X, Dong P, Ji H, Shao G, Liu Q (2019) Mechanical power loss and meshing efficiency prediction of involute Spur gear. Mech Eng Technol 8(3):175-187

14. Chen J, Liu S, Zou also known as (2017) Research on calculation of friction power loss of bevel gear with time-varying parameters. Mach Des Manuf (07):60-64.

15. Marques PMT, Martins RC, Seabra JHO (2016) Power loss and load distribution models including frictional effects for spur and helical gears. Mech Mach Theory 96:1-25

16. Wang C, Gao C, Jia H (2012) Power losses of sliding friction based on meshing characteristics of double helical gears. Zhongnan Daxue Xuebao (Ziran Kexue Ban)/J Central South Univ (Sci Technol) 43(6):2173-2178

17. Chen R, Zhou J, Sun W (2018) Dynamic characteristics of a planetary gear system based on contact status of the tooth surface. J Mech Sci Technol 32:69-80

18. Mohammadpour M, Theodossiades S, Rahnejat H (2016) Dynamics and efficiency of planetary gear sets for hybrid powertrains. Proc Inst Mech Eng Part C J Mech Eng Sci 230(7-8):1359-1368

19. Wu Y, Wang J, Han Q (2012) Contact finite element method for dynamic meshing characteristics analysis of continuous engaged gear drives. J Mech Sci Technol 26:1671-1685

20. Shen J, Hu N, Zhang L, Luo P (2020) Dynamic analysis of planetary gear with root crack in sun gear based on improved timevarying mesh stiffness. Appl Sci 10(8379):8379

21. Liu W, Zhao H, Lin T et al (2020) Vibration characteristic analysis of gearbox based on dynamic excitation with eccentricity error. J Mech Sci Technol 34:4545-4562
22. Wang H-F (2014) Dynamic analysis of the double helical planetary gear trains considering tooth friction. Nanjing Univ Aeronaut Astronaut 25-29

23. Li F, Yuan R, Zhu H, Cao P, She D (2020) Dynamic characteristics of spiral bevel gears considering tooth surface friction. J Aerosp Power 35(8):1687-1694 (in chinese)

24. Li X, Xu J, Yang Z (2020) The influence of tooth surface wear on dynamic characteristics of gear-bearing system based on fractal theory. J Comput Nonlinear Dyn 15(4):041004

25. Ouyang T, Huang G, Chen J, Gao B, Chen N (2019) Investigation of lubricating and dynamic performances for high-speed spur gear based on tribo-dynamic theory. Tribol Int 136:421

26. Wang B, Chen XB (2014) Meshing efficiency of involute helical gears based on elastohydrodynamic lubrication. Adv Mater Dev Appl Mech 597:450-453

27. Li S (2015) A computational study on the mechanical power loss of a spur gear pair under the thermal tribo-dynamic condition. In: Proceedings of the ASME design engineering technical conference, vol 10

28. Li S et al (2009) Influence of design parameters on mechanical power losses of helical gear pairs. J Adv Mech Des Syst Manuf 3(2):146-158

29. Thirumurugan $R$, Muthuveerappan G (2013) Study on mesh power losses in high contact ratio (HCR) gear drives. In: 1st International and 16th national conference on machines and mechanisms, iNaCoMM 2013, pp 169-176

30. Montagnier O, Hochard C (2014) Dynamics of a supercritical composite shaft mounted on viscoelastic supports. J Sound Vib 333:470

31. Dastjerdi S, Akgöz B, Civalek Ö (2020) On the effect of viscoelasticity on behavior of gyroscopes. Int J Eng Sci 149:103236

32. Quanzhong W, Guorong C (1993) Improvement of the determination method of $a$ and $\beta$ constants in proportional damping. J Nanjing For Univ (Nat Sci Ed) 04:88-91

Publisher's Note Springer Nature remains neutral with regard to jurisdictional claims in published maps and institutional affiliations. 